\title{
About Our Theme - Design and Resilience
}

JOHN FOLAN

Carnegie Mellon University
JULIE JU-YOUN KIM

Georgia Institute of Technology

"Resilience is the intentional design of systems that have capacity to adapt and sustain vitality in response to stresses or disturbances. Resilience 1) is multi-scalar, 2) benefits from redundancy, 3) anticipates dynamic futures, 4) equitable, 5) nonabsolute, and 6) predicated on understanding of condition."

The working definition referenced above is the thread that we used to tie together the content of four sessions and frame discourse at the 2018 AIA Intersections Symposium on Design and Resilience. Three separate, but related, contextual frameworks - Technological, Ecological, and Sociological - provided a platform for a fourth discussion that addressed synthesis and action. Offered as part of the 2018 AIA Conference on Architecture and curated in collaboration with a cohort of moderators, this format represents a radical departure from previous Intersections Symposia. With an articulated mission of bridging the gaps that exists in education, research and practice, the Intersections Symposium is a joint venture between the AIA and ACSA. The move to construct the 2018 symposium as a constellation of sessions delivered throughout the programming of the AIA Conference promised to broaden discourse and make a forum more accessible to the voices who will reinforce the connections between practice and the academy.

Consistent with that aspiration, the sessions were conceived of and structured as forums for discussion. Presentations were abbreviated and the content oriented toward illustrating major themes, either consistent, or in opposition with one another. The moderators for each session were empowered to calibrate the conversation around thematic content contained in this volume, but were asked specifically to avoid making this a platform for dissemination of published content. The moderators selected for the thematic sessions are leading practitioners in the areas of technology, ecology and social justice, representing the practices of Kieran Timberlake, Kennedy Violich Architecture, and MASS Design Group respectively. Beyond being well respected design practitioners with domain expertise, all three architects represent practices that have research units, remain engaged in contemporary educational pedagogy development, and address the breadth of topic scope with different hierarchical priority. In this form, the symposium sessions positioned themselves as units that could stand autonomously, or relate across a broader discourse. The content of this volume includes six projects, each reinforcing actionable models

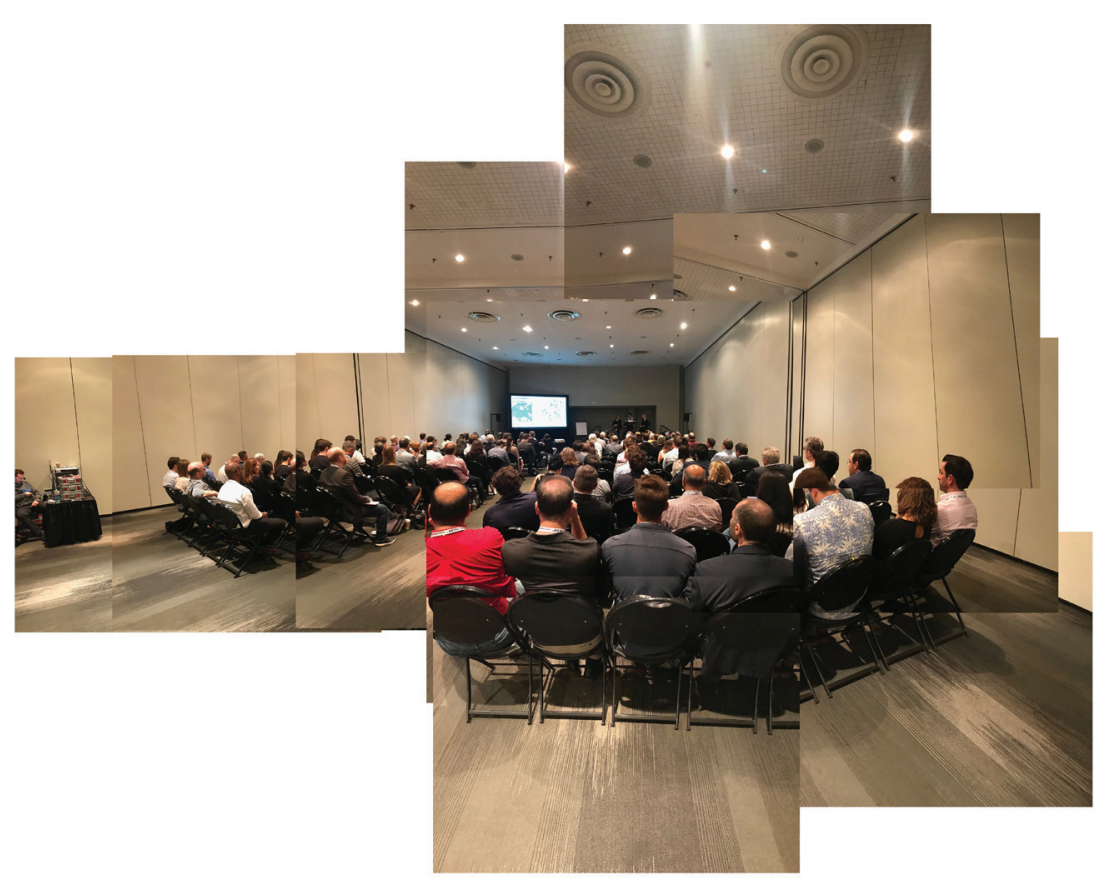
for systems of architecture as they relate to ecological, technological, and sociological resilience. Presented here in comprehensive form, the writing underscores thematic content discussed in New York City on June 22, 2018. Across all three sessions, and the associated writing included in this volume, we see consistent themes in systems, place, scale, and metrics emerge. The evidence of that consistency was affirmed as moderators and participants convened to speculate on actionable opportunities for both practice and the academy. The lenses through which opportunity was explored in discourse, and which is affirmed in the cases/writing finds its bearing in the session synopsis which follow. 
Framing Technology and Resilience How can technology aid our search for design and resilience? In what ways are we proposing innovative resilient design solutions via the integration of data, sensors, biomimicry, materials development and testing, structural innovations, energy modeling, artificial intelligence, augmented reality, and virtual reality? Is there current research occurring in academic studios and labs that can impact professional practices?

Led by Billie Faircloth, AIA, Kiernan Timberlake, the authors addressed design issues, while engaging citizens and other stakeholders, to showcase cutting edge research in adaptive building systems, material sciences, environmental, urban ecology, adaptation and embedded technologies, particularly as they relate to climate change, resiliency and sustainability. One of the projects offers strategies for resilient communities that face challenges and opportunities to live with water. These strategies include urban hydrology management, citizen-engaged science, visualization strategies, data and sensors, and urban prototyping (Cordula Roser Gray, AIA, Tulane). The second project shares the results of several senior research studios focused on material technologies, kinetics, synthetic biology and robotics in architectural systems and how technology can empower architecture to connect spaces, users and environment as one path to resilience (Vera Parlac, U. of Calgary).

Framing Ecology and Resilience How do we design more resilient habitats? What theories, systems, materials, and/or processes are being explored that embrace these challenges and advance resiliency and sustainable use? What new opportunities might present themselves as we innovate and explore solutions to these critical issues?

The selected projects for this session address ecological design and resilience through infrastructure, materials, fabrication, building performance, aesthetics, and parametric tools. Facilitated by Shawna Meyer, AIA, Kennedy \& Violich, the authors presented compelling cases for how nature informs design and produces resilient structures that please the senses and save the planet. The audience heard two different strategies for leveraging ecology to produce different scales of products. One of the projects combines innovative design strategies with advanced R\&D concrete mixes and fabrication techniques. The resulting concrete modules encase mangrove seedlings, while concrete fins below water create new ecological habitats (Julie Larsen, Assoc. AIA, Syracuse). The second research project presents student research using parametric design tools, multi-modal methods, and performative material systems as part of a larger design challenge (Sandy Stannard, Cal Poly). In each example, "performance" goes beyond the basics, informed design, and identifies an environmental necessity - need for water, need for cleaner air - based on the project situation.

Framing Social Resilience Communities around the world are struck with sudden shocks and disturbances due to social, political and environmental change. What does design and resilience mean for those who inhabit our built environment? How can design and construction impact educational outcomes? The spread of disease? Poverty? Policy? Security? How do we engage stakeholders in the design and resilience process?

MASS Design's Alan Ricks, AIA, joined by Colloqate's Bryan Lee, facilitated an interactive discussion about social justice, equity, and inclusion. The audience heard two very different proposals for addressing social resilience and design in communities. At one scale, pneumatic technology, mobility, sociability, and environmental responsibility through the design and fabrication of a prototype nomadic inflatable structure offer answers to a community need (Whitney Moon, U. Wisconsin). The second project in Boston focused on urban resilience for the homeowner by addressing the existing urban fabric of repetitive, residential buildings that architects have historically neither designed nor studied. Through a data-model developed from publicly available information, an online app was created to simulate comfort, energy use, response to natural hazards, etc. (Michelle Laboy, Northeastern U.) Both of these projects reinforce the idea that social resilience addresses changes resulting from environmental, social or political stresses. Fundamental to both projects is the engagement of stakeholders in the process.

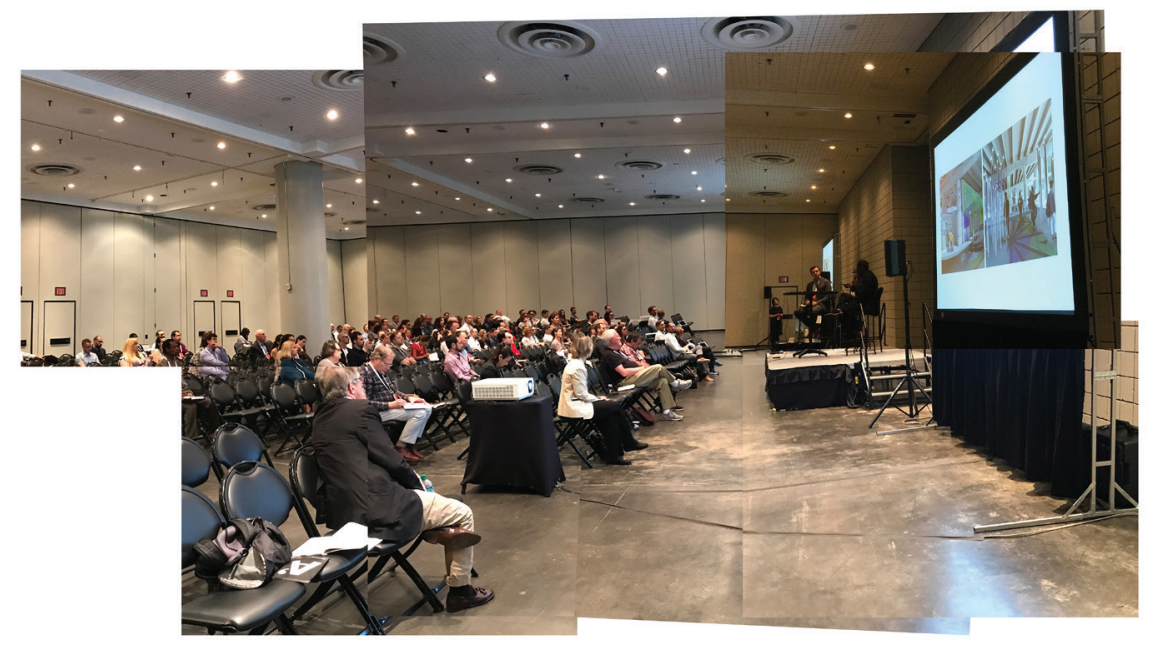



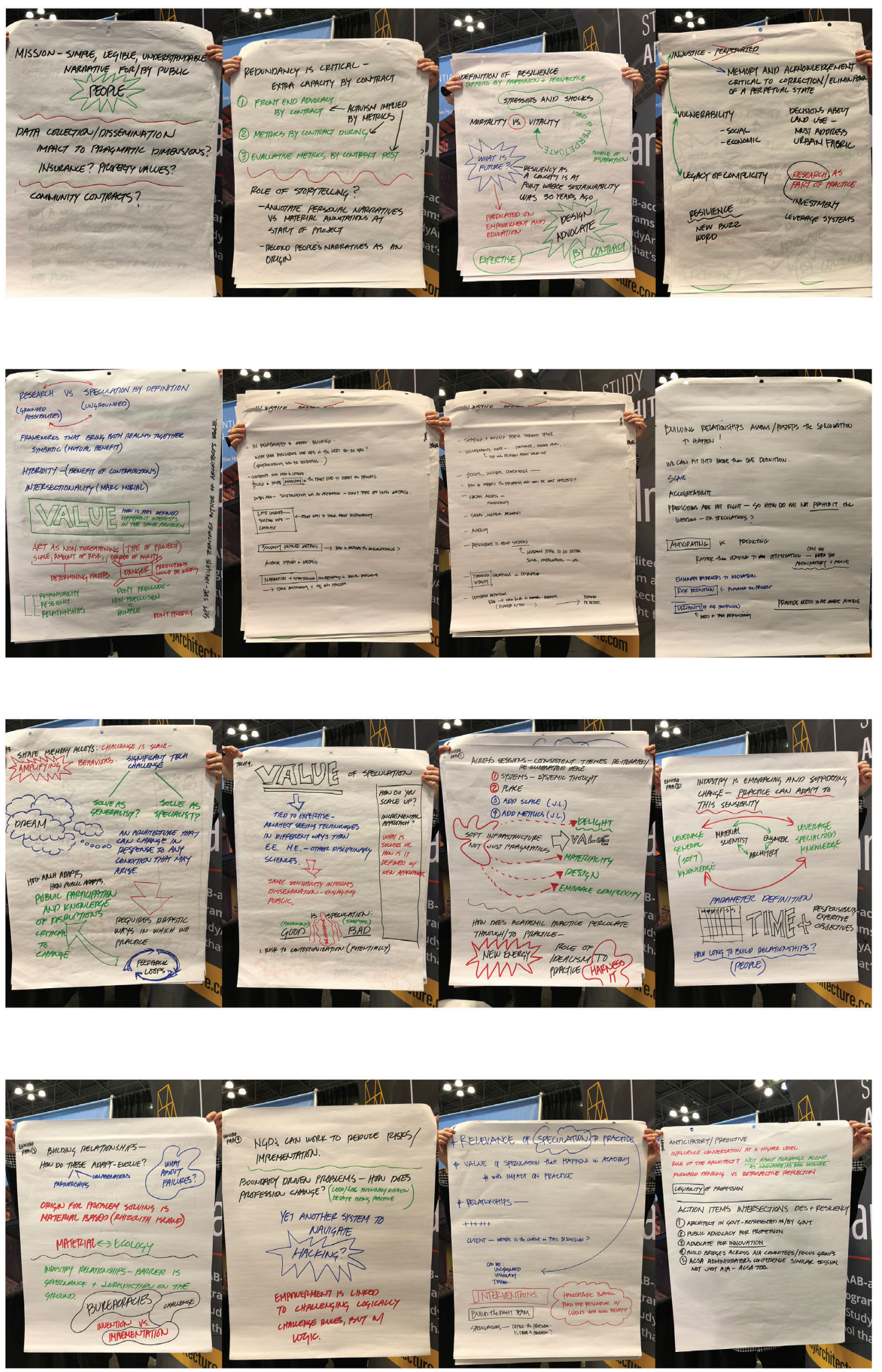
Framing Resilience: The Wrap-Up Our vision for this symposium leveraged the partnership between the American Institute of Architects (AIA) and the Association of Collegiate Schools of Architecture (ACSA) to extend discourse at the intersection of education, research, and practice. As we considered the structure for the 2018 Intersections Symposium, we saw an opportunity to further strengthen the tie between the academy and practice via brokered engagement between an invited moderator, the authors, and the audience. We envisioned three interactive discussions, each led by a leader in the profession whose own efforts bridge research and practice. While the content of the accepted authors' papers directed the structure of the discussion, the moderators framed the respective conversations with a series of provocations designed to elicit open and lively dialogue between the authors and the audience. In a final wrap-up session, the three invited moderators and co-chairs engaged in an open discussion with each other and the audience on the nature of research, practice, and technology framed through ideas of resilience.

Each of the three sessions foreground a discreet lens - technological, ecological, and sociological. Taken collectively, however, the projects all asked us to reconsider the residual impact on the user and on the environment. The question of value-added ultimately rose to the surface.

- What is the value of speculation?

- Is it "living in a dream" to imagine an architecture that can change in response to environmental conditions?

- How does academic practice thread into practice?

- How can the profession leverage industry relationships when governance and jurisdictions present barriers?

- Where are the opportunities to exploit the differences between research and speculation, or, in other words, between grounded possibilities and ungrounded ones?

Are they really so very different in the end? Given the lively and energetic debate between an audience of practitioners and the authors, it was clear that this topic was timely and relevant to contemporary discourse in schools and in practice. The desire to find ways to build relevance to risky experimentation and implementation resonated across the discussions. Critical to continuing the dialogue is building relationships to start a feedback loop enabling new models of practice and of education. We must continue to challenge the role of the architect, as not just about buildings, but about innovation and risk. The issues raised in this symposium and in these proceedings are just the beginning of a conversation that should continue.

As co-chairs of the 2018 Intersections Symposium, we would be remiss if we did not recognize the efforts of our predecessors. Nothing is achieved in a vacuum and the ability to reconsider the format has been the privilege of having charted territory to build from. Without the support of the American Institute of Architects and Association of Collegiate Schools of Architecture, and their foresight in providing a platform for this exchange, the work of everyone represented in these proceedings would not be possible. We would like to express our gratitude to co-conspirators in the production of this volume, Eric Wayne Ellis, ACSA Director of Operations and Programs, and Nissa DahlinBrown, AIA Director of Higher Education. Without their efforts and support, the diversity and scope of what is discussed would not have been as broad or focused in setting the stage for future Intersections Symposia.

John Folan and Julie J. Kim, Co-Chairs 